\title{
Tools for Teaching
}

\section{Ethics of Product Endorsement: Taking a Look at Freebies}

\author{
Barbara A. Hotelling, BSN, CD (DONA), LCCE, FACCE
}

BARbara Hotelling is an independent childbirth educator and doula in Rochester Hills, Michigan. She currently serves as president of Lamaze International and as a faculty member of Lamaze. She has also served as president of Doulas of North America (DONA) and chair of the Coalition for Improving Maternity Services (CIMS).

\begin{abstract}
Childbirth educators are potentially a large vehicle for marketing promotions to young and purchasing parents. Many free materials-educational matter and product samples-are available for the educator's own use and for distribution to the parents who attend class for evidence-based information. In this column, the author encourages childbirth educators to use good judgment in selecting materials that will protect normal birth, encourage positive parenting, and promote breastfeeding. Educators must consider the effect a brand name will have on the purchasing power of parents and whether or not the materials or samples will undermine breastfeeding efforts.

Journal of Perinatal Education, 13(3), 7-9; product endorsement, childbirth education.
\end{abstract}

DOI: $10.1624 / 105812404 X 1716$

I remember well, so many years ago, the excitement of having mass-produced charts for my classes (instead of my homemade plastic-covered drawings), getting videos to hand out to parents, and anticipating the arrival of boxes filled with freebies. I hear that same excitement in the voices of new childbirth educators as they receive handouts from many different organizations. It's a great feeling to be able to give something tangible to parents. When do we become experienced enough, though, to recognize the harm we do in being nonselective in the handouts we so freely distribute?

What's the harm in giving out loads of free coupons and informational magazines? Aren't the articles all pretty much alike? Does it matter if we accept money for distributing handouts or showing videos as long as 


\section{Tools for Teaching-Ethics of Product Endorsement: Taking a Look at Freebies}

we use the money for teaching materials or scholarships for our classes?

\section{Problem \# 1}

Not all materials abide by the United Nation's Children's Fund (UNICEF) and World Health Organization's (WHO) International Code of Marketing of Breast-milk Substitutes (WHO, 1981). Some time ago, you may have received "The Thinking Educator's At-A-Glance Comparison," a Lamaze Parents Magazine mailing that examined the four most widely distributed childbirth magazines. Among Lamaze Parents Magazine, American Baby Childbirth, Baby Talk Childbirth Guide, and New Parent, Lamaze Parents Magazine was the only publication in compliance with the WHO guidelines. Additionally, Lamaze Parents Magazine (LPM) had the most number of pages and professionally written articles among the four publications. That's pretty amazing, considering $L P M$ accepts no formula or bottle advertising. Many advertising dollars are lost to LPM by the magazine's adhering strictly to the advertising guidelines set by the Lamaze International Board of Directors. So what's the big deal? Shouldn't parents have all the information to make informed choices?

What message are we sending to parents when we teach the importance of human milk for human babies in class and, then, distribute materials that do not comply with WHO guidelines? The harm is that our breast-milk message is attacked when we hand out materials that show photos of formula-fed infants smiling into their loving mothers' eyes versus breastfeeding mothers with their breasts abnormally exposed and looking tired and harried. The harm is that parents receive coupons and mail-in offers for breast-milk substitutes that can adversely affect their success at breastfeeding.

In its 1998 publication titled Evidence for the Ten Steps to Successful Breastfeeding, WHO presented studies that supported how the use of formula or other breast-milk substitutes reduces breastfeeding rates:

Perez-Escamilla et al. (1994) performed a meta-analysis of six experimental studies (Bergevin, Dougherty, \& Kramer, 1983; Guthrie et. al, 1985; Evan, Lyons, \& Killien, 1986; Feinstein et al., 1986; Frank et al., 1987;
Dungy et al., 1992). Studies compared groups receiving commercial discharge packs, which included samples of breast-milk substitutes, with groups that received no formula but educational pamphlets, breast pads, breast cream, breast pumps, bottles of water, nonspecified materials, or nothing at all. Five studies were performed in industrialized countries, one in the Philippines. The rates of full breastfeeding at 1 month and any breastfeeding at 4 months were significantly lower in the groups receiving samples of formula or other breast-milk substitutes. Perez-Escamilla concluded that commercial discharge packs are associated with reduced breastfeeding rates, especially among groups at risk such as primiparae and low-income women in developing countries (p. 52).

When we consider that conditions such as diarrhea, respiratory tract infections, otitis media, pneumonia, urinary tract infections, necrotizing enterocolitis, and invasive bacterial infections are lower in incidence or severity in breastfed infants, we are adding to the problem, not the solution, when we distribute materials that promote breast-milk substitutes. The goals of Healthy People 2010 support increasing the rates of breastfeeding as a compelling public-health endeavor (U.S. Department of Health and Human Services, 2000a).

\section{Problem \# 2}

Another feature of Lamaze Parents Magazine lacking in the other publications is a commitment to normal birth information that is evidence-based. The information our parents get from $L P M$ is written and edited by the master faculty of Lamaze International and other experts and is scrutinized yearly to ensure the messages readers receive are based on the most up-todate research. Our parents complain that too many "theories" exist about birth, breastfeeding, and parenting and that they never know what information to trust. We educators can be reassured that the information we distribute is not only accurate but also empowering when we give copies of $L P M$ as reference materials.

\section{Problem \# 3}

When we decide to use a portion of class time to show a product video, our action definitely endorses that 
product. If the product is controversial, the video makes our parents more familiar with the positive side of the discussion because the favorable aspects are presented in a pleasing, enticing media format. If we want to present the other side of the product debate, it will be done in a class discussion not nearly as lovely or impressionable as the message just witnessed in the video.

If the product isn't controversial and fits in with Lamaze International's vision statement, there is still the problem that the video or materials do not give equal time to other companies who offer the product, perhaps at a savings to your class participants. This problem also extends to written handouts, charts, and goodies with product names imprinted on them.

Let's say that we are given pens and notepads from a company that makes lanolin cream for breastfeeding mothers. We say to ourselves that this is a great product and giving out the sample materials won't harm anyone. When these parents go to shop for lanolin creams, they have been familiarized with the brand name we promoted and will have positive feelings for that brand, even though other brands may work equally well and cost less. In giving out the free materials, we have endorsed not only a good product but also one specific manufacturer.

Of course, we walk a fine line with our own Lamaze publications. We do accept advertising money for our own publications, such as Lamaze Parents Magazine. This advertising money enables us to reach millions of expectant parents with the Lamaze philosophies of birth, parenting, and breastfeeding and with information that promotes normal birth and is written by our own educators. When you distribute materials published under the Lamaze name, you can be sure that the message promotes the Lamaze mission and that the advertisers are in compliance with WHO and UNICEF's Code of Marketing of Breast-milk Substitutes.

\section{Problem \# 4}

Accepting money for distribution of product materials promotes those products for both the parents and instructors. When we accept money, it changes our feelings about the product in a more positive way. We are more likely to soften the controversial aspects of the product in our class discussions. We may tell ourselves that the video or printed material is evenly balanced between pros and cons. However, the company's board of directors isn't providing advertising dollars for benevolent reasons. The purpose of the freebies is to increase familiarity with the brand name and product. If the freebies don't accomplish that goal, some company heads will roll.

\section{Conclusion}

Being selective in choosing our handout materials means that we value the essence of normal birth, parenting, and breastfeeding and conveys that message to our parents. It also sends a message to advertisers to place their dollars into publications that support WHO guidelines and normal birth. It is one way childbirth educators can slowly but surely change the culture of birth from one that is mesmerized by glitz and technology to one that values safe and satisfying birth. We are all demoralized by the birth culture that overlooks the evidence for normal birth and chooses what is expected to be a guaranteed safe, painless experience. As Healthy People 2010 states: "The health of mothers, infants, and children is of critical importance, both as a reflection of the current health status of a large segment of the U.S. population and as a predictor of the health of the next generation" (U.S. Department of Health and Human Services, 2000b).

\section{References}

U.S. Department of Health and Human Services. (2000a). Health and Human Services blueprint for action on breastfeeding. Washington, DC: Author, Office on Women's Health.

U.S. Department of Health and Human Services. (2000b). Healthy people 2010. Washington, DC: Author. Retrieved May 28, 2004, from http://www.health.gov/healthypeople

World Health Organization. (1981). International code of marketing of breast-milk substitutes. Geneva, Switzerland: Author. Retrieved May 28, 2004, from http:// www.who.int/child-adolescent-health/New_Publications/ NUTRITION/hiv_and_infant_feeding.htm

World Health Organization. (1998). Evidence for the ten steps to successful breastfeeding (revised). Geneva, Switzerland: Author. 